\title{
\&netsafe
}

netsafe.org.nz

\section{Factsheet: Who is sending and sharing potentially harmful digital communications?}

\author{
Prepared by Neil Melhuish \& Dr. Edgar Pacheco
}

This factsheet presents findings from a quantitative study looking at adults' experiences of sending and sharing potentially harmful digital communications in New Zealand.

Typically research into harmful digital communications focuses on the experiences of those on the receiving end - the victims. However, to better address the distress and harm caused, information is needed about the people sending and sharing potentially harmful messages and posts. In this study we asked adult New Zealanders whether they had sent potentially harmful digital communications in the previous year and if so, how often they had done this, who they were sent to, the channel(s) they used, and the reason for doing this.

\section{Highlights}

- Around 1 in 10 adult New Zealanders had sent or shared at least one potentially harmful digital communication in the previous 12 months.

- It was most common for people to say offensive things about someone, but they also engaged in a range of behaviours such as sharing someone's intimate images without their permission or encouraging other people to send hurtful messages to someone.

- Over a quarter of senders said they did this for a joke, while around 1 in 10 wanted to influence someone's behaviour or thoughts, scare or embarrass them, and 1 in 20 were motivated by reasons such as revenge, money and sexual pleasure.

- Nearly half of the people sent these communications were family or friends, while about 1 in 10 people were strangers.

- Around 8 in 10 of people sending potentially harmful digital communications had also received them. In contrast, only 1 in 4 of receivers said they also sent such material to others. 


\section{Sending harmful digital communications}

Eleven percent of New Zealand adults have personally sent or shared at least one type of potentially harmful digital communication', with around $80 \%$ of them ( $9 \%$ of all adults) having done this more than once.

\section{Around 1 in 10 New Zealand adults send or share potentially harmful digital communications}

Percentage of NZ adults who said they had sent or shared potentially harmful digital communications in the last 12 months.

$11 \%$ Sent or shared at least one type of harmful digital communication

$9 \% \quad$ Sent or shared a harmful digital communication two or more times

$3 \% \quad$ Sent or shared a harmful digital communication once 
The most frequent type of communication "said offensive things about someone" $6 \%$ of the population). There were also two groups of less prevalent behaviours that 2 or $3 \%$ of people said they had engaged in.

Six percent of New Zealanders said offensive things about someone else in a communication

Prevalence of different types of harmful digital communications sent.

\section{$6 \%$}

- Said offensive things about someone

\section{$3 \%$}

- Tried to embarrass someone online

- Attempted to get someone excluded from a friendship group

- Made a sexual advance that they were not sure was wanted

- Included violent or sexual content

- Encouraged other people to send hurtful messages to someone

\section{$2 \%$}

- Regularly monitored someone's online activity to influence behaviour or thoughts

- Physically threatened someone

- Shared intimate images or recordings of someone without their permission

- Made a false statement about someone's personal or professional life

- Tried to get someone to hurt themselves

- Was harmful to someone else in another way 
Nearly half of the time, potentially harmful digital communications were sent in relation to an issue that was playing out purely online (46\%), but in around a quarter of instances the online actions were part of a wider issue happening offline (24\%).
1 in $\mathbf{4}$ harmful digital communications were sent as part of an issue that is also taking place offline, while nearly half related to an online issue only

Percentage of actions that took place online only or as part of a wider issue happening offline

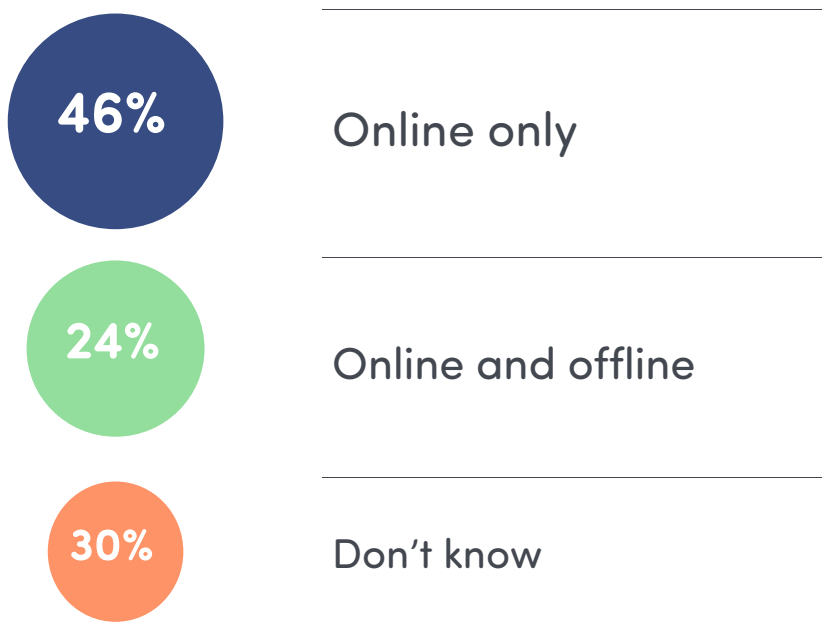

Base: Participants who sent at least one harmful digital communication $(n=133)$

\section{Relationship of the sender to receiver}

In terms of the relationship between sender and receiver, the most likely groups of people to be sent a potentially harmful digital communication were friends (29\%) and family members (20\%). About 1 in 10 people said they sent the communication to a stranger (13\%).

\section{Nearly half of the people that harmful digital communications were sent to are family or friends}

Percentage of people being sent potentially harmful digital communications by group

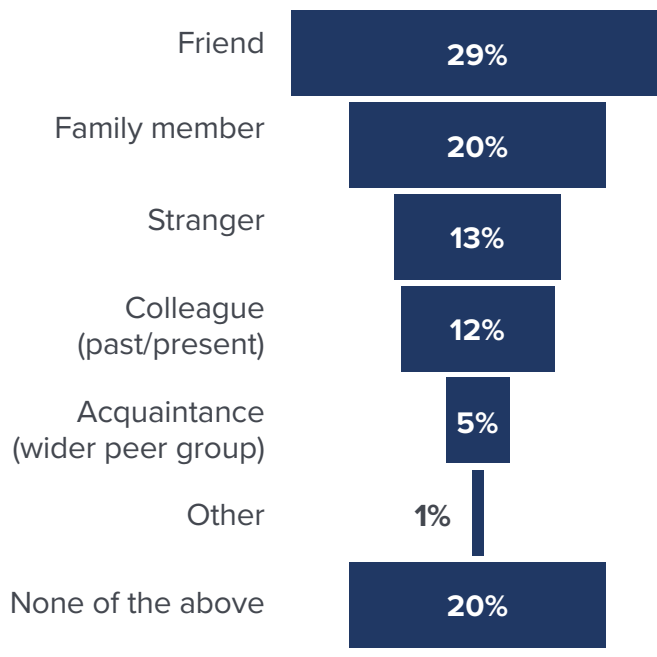

Base: Participants who sent at least one harmful digital communication $(n=133)$ 


\section{Overlap between senders and receivers}

About a third (34\%) of people said they had received an unwanted digital communication in the previous year. Of these a minority of around 1 in 4 had sent as well as received such communications ( $9 \%$ of all New Zealanders). In contrast, a large majority (around 8 in 10) of the $11 \%$ of people sending harmful digital communications had also received them.

\section{Nearly 1 in 10 New Zealanders have both sent and received harmful digital communications (9\%)}

Percentage of people sending, receiving, and both sending and receiving harmful digital communications

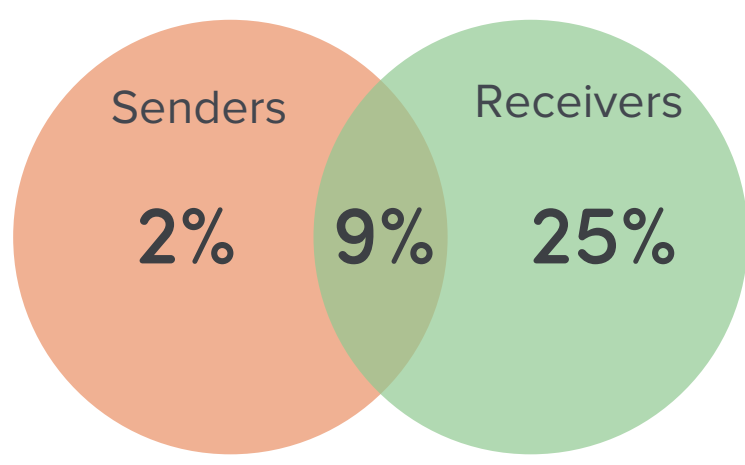

Base: All participants $(n=1,161)$

Note, 'neither' was 53\%, and 'not sure' or 'not answered' were $11 \%$ in total.

\section{Communication channel used}

Mobile phone messages were the most common channel used for sending communications (39\%), while $34 \%$ posted to their own social profile and $10 \%$ to others' social media. Other relatively popular modes were email (20\%), and dating apps or websites (10\%).

\section{Mobile phone messages and social media posts are the most common platforms people used to send harmful digital communications}

Prevalence of the channels used to send harmful digital communications (\%).

\begin{tabular}{|r|c|}
\hline Text or message via mobile phone & $39 \%$ \\
\hline Post on your social media profile(s) & $34 \%$ \\
\hline An email & $20 \%$ \\
\hline Post on others' social media, blogs, forums & $10 \%$ \\
\hline Online dating website or app & $10 \%$ \\
\hline News site's discussion or comment section & $6 \%$ \\
\hline Online gaming & $4 \%$ \\
\hline
\end{tabular}

Base: Participants who sent at least one harmful digital communication ( $n=133$ ) 


\section{Reason for communication}

A range of reasons for sending or sharing a potentially harmful digital communication were given.

Around a quarter said it was sent as a joke (28\%), but gave reasons such as influencing someone's behaviour or thoughts (14\%), to scare (8\%) or embarrass (6\%) them, or to get revenge (4\%).

\section{The most frequently given reason for sending a potentially harmful digital communication was 'for a joke'}

Prevalence of the different reasons New Zealand adults gave for sending or sharing potentially harmful digital communications

\begin{tabular}{|c|c|}
\hline For a joke & $28 \%$ \\
\hline To influence their behaviour or thoughts & $14 \%$ \\
\hline To scare them & $8 \%$ \\
\hline To embarrass the person & $6 \%$ \\
\hline To get revenge or get back at them & $4 \%$ \\
\hline To get money from them & $3 \%$ \\
\hline To get more images or videos from them & $2 \%$ \\
\hline For sexual pleasure & $1 \%$ \\
\hline Other & $19 \%$ \\
\hline Don't know & $16 \%$ \\
\hline
\end{tabular}




\section{About Netsafe research}

Netsafe carries out research as a wider part of its statutory role as approved agency under the Harmful Digital Communications Act 2015 to inform the design and delivery of its resources and services and provide research-based evidence for others working to address online safety issues. The topic of this report sits within the scope of the Act's ten communications principles that together describe a range of potentially harmful types of online communications ${ }^{2}$.

To contact Netsafe for more information about its research programme or how you can contribute contact: research@netsafe.org.nz

For more information about New Zealand's Harmful Digital Communications Act 2015 and Netsafe's Approved Agency role visit: https://www.netsafe.org.nz/hdc-act/

\section{What's next on this topic?}

Netsafe is contributing to a book exploring international perspectives and experiences of Technology-Facilitated Violence and Abuse. This looks at data used in this report in greater detail to explore demographic factors behind harmful digital communications in New Zealand.

Netsafe is also working with the Australian Office of the eSafety Commissioner and UK Safer Internet Centre to contribute to a shared report about the perpetration of online violence and abuse.

Later in 2020, Netsafe will repeat this study using the same methodology to establish trend data for the perpetration of harmful digital communications.

2 See Harmful Digital Communications Act 2015, s 6(1). 


\section{Methodology}

The data for this study was collected as part of Netsafe's 2019 Annual Population Survey (APS), a large quantitative study that explores the interaction between adult New Zealanders and digital technologies in the context of the Harmful Digital Communications Act 2015.

The survey was conducted with 1,161 New Zealanders in June 2019 by Colmar Brunton's Social Research team. Participants came from a representative sample of New Zealand adults (aged $18+)$ in terms of age, gender, ethnicity, and region weighted to the 2013 Census count. The maximum margin of error for the whole sample is $\pm 3.1 \%$ at the $95 \%$ confidence level. Note, percentages in figures and tables may not total exactly $100 \%$ due to rounding or because participants were allowed to choose multiple answers to some questions.

The communications principles were used to inform the survey questions. Specifically we asked about communications people had sent or shared that:

- Physically threatened someone

- Attempted to get someone excluded from a friendship group

- Tried to embarrass someone online

- Said offensive things about someone (e.g. the way they look, how they behave, or what they believe in)

- Included violent or sexual content

- Was a false statement about someone's personal or professional life

- Was a sexual advance toward someone that you were not sure was wanted (e.g. messages about sex, naked selfie, images or video live stream)

- Involved regularly monitoring someone's online activity in order to influence their behaviour or thoughts

- Shared intimate images or recordings of someone without their permission

- Encouraged other people to send hurtful messages to someone else

This study provides new insights into adult New Zealanders' engagement in sending and sharing potentially harmful digital communications. However, there are limitations to this study. These include the potential social desirability bias in participant responses i.e., people may provide socially acceptable answers rather than disclose accurate information about their behaviour. This limitation is mitigated by the anonymous conditions of the survey. Another limitation is that quantitative surveying does not allow deeper exploration of the context, for example, to take a closer look at the behaviours that may have been consensual or that the receiver did not experience as harmful. Finally, a note on gender: as only $0.4 \%$ of participants identified themselves as gender diverse it was not possible to draw statistically relevant conclusions for this group. 
FACTSHEET: WHO IS SENDING AND SHARING POTENTIALLY HARMFUL DIGITAL COMMUNICATIONS?

Wellington, New Zealand, June 2020

www.netsafe.org.nz

research@netsafe.org.nz

Retrieved from: https://www.netsafe.org.nz/sending-sharing-potentially-HDC-2020

ISBN: 978-0-473-52765-5

\section{ATTRIBUTION-NONCOMMERCIAL-SHAREALIKE}

(c) () () $\mathrm{https://creativecommons.org/licenses/by-nc-sa/4.0/} \mathrm{[English]}$

https://creativecommons.org/licenses/by-nc-sa/4.0/legalcode.mi [Te Reo Māori] 